\title{
Predictive Estimation of Sliding Bearing Load-Carrying Capacity and Tribological Durability
}

\author{
Myron Chernets ${ }^{1}$ - Marek Opielak ${ }^{2}$ - Anatolii Kornienko ${ }^{1, *}$ - Oleg Radko ${ }^{3}$ \\ ${ }^{1}$ Aerospace Faculty, National Aviation University, Ukraine \\ 2Lublin University of Technology, Poland \\ ${ }^{3}$ National Defence University of Ukraine named after Ivan Cherniakhovskyi, Ukraine
}

A computational method is presented as a method for solving a plane contact problem of the theory of elasticity to determine the contact strength and tribological durability of sliding bearings. The effect of load and radial clearance on the initial contact pressures and their reduction due to wear is studied. The durability of the bearing is estimated. Qualitative and quantitative regularities of changes in contact parameters and durability from the factors under study are established. In particular, it has been shown that both contact angles and maximum contact pressures are approximately linearly dependent on the load, and the durability decreases nonlinearly with increasing load.

Keywords: sliding bearing, wear-contact problem, contact and tribocontact parameters, wear, durability

\section{Highlights}

- A computational method for sliding bearings is presented.

- A tribokinetic wear model for sliding friction has been developed.

- Evaluation of contact pressures and durability has been carried out.

- Regularities of the influence of wear on contact characteristics and resources have been established.

\section{INTRODUCTION}

The use of sliding bearings as one of the common friction units (Fig. 1) currently remains quite significant, where the use of rolling bearings is impossible or impractical. The main recommendations for their use are high load capacity, use at miniature or large shaft diameters, at significant speeds, at shock loads, small radial dimensions, low noise, damping capacity, etc. The range of their application in practice is very diverse [1]. They work in various conditions, not only at liquid conditions but also at boundary and dry friction in separate cases. Under certain operating conditions, special alloys can be used to make the shaft, for example [2]. It should be noted that the number of new types of composite materials for metal bearings is growing rapidly [3]. Therefore, the estimated assessment of their bearing capacity, wear, and durability at the design stage is an urgent task.

The solutions of the corresponding wear-contact problems for such sliding tribosystem are known in the literature [4] to [16]). In particular, in [7] and [8], a model of the sliding bearing wear in conditions of boundary friction was obtained in the form of dependence of the wear rate on the dimensionless complexes of contact pressure and sliding velocity. The parameters of wear resistance in the model were determined by the calculation-experimental method on the basis of wear tests with the "cone - three balls" structure under variable contact conditions.
Such a non-standard friction structure (ISO 71482) significantly limits the use of this wear model. Paper [9] presents the results of an experimental and numerical study of fibre-reinforced polymer bearings. The authors developed a two-dimensional finite-element model to study the stresses in the bearing and researched three-dimensional quasistatic and two-dimensional dynamic models. A study on the effect of the clearance on the contact stresses and kinematics of large-scale composite bearings in [10] was conducted experimentally, using the finite element method. The results of the wear study are not given. Paper [11] presents an adaptive wear-modelling method in plain bearings. Validation was done for a laminated polymeric composite bearing. A study of the effect of clearance on the wear and the evolution of contact pressure due to wear was performed. In [12], the method of triboelements and the modelling of the behaviour of sliding tribosystems on the basis of Archard's law of abrasive wear with use of ANSYS are presented. Paper [13] aimed to study the wear of a fine elastic layer with the rigid bearing and shaft with the same method. Numerical analysis of the effect of the external load scattering and the initial radial clearance in the bearing on its wear was carried out. Paper [14] presents the results of a numerical simulation with the triboelement method to determine the wear of a thin elastic layer on a hard bushing of a cylindrical linear plain bearing. These works use Archard's law of wear. Methods for estimating the parameters of the 
durability model under the mechanism of high-cycle fatigue under sliding friction conditions are proposed in [15]. The results are recommended for analysing the reliability and durability of friction units of machines under fatigue wear conditions. For the numerical modelling of the wear kinetics of tribosystems, an iterative approach is presented in [16], which takes into account the discrete states and operational factors affecting wear. The wear of the tribosystem elements is calculated.

The abovementioned methods have not yet found proper practical application due to the use of a simplified Archard's law of abrasive wear assuming the wear intensity linear dependence on the contact pressure and the friction path, although this type of wear is unacceptable in sliding bearings. Today, in engineering practice and in the design calculations of sliding bearings, it is customary to use two main parameters: the average pressure $p$ and the parameter $p v$. This simplification is very approximate, because the contact area characteristics depend not only on the load and the diameter of the shaft journal but also significantly on the radial clearance in the bearing and the elastic characteristics of the element materials. The last of the specified significant factors of influence are not considered in any way in the specified criteria, and the problem of predictive evaluation of sliding bearings durability at the design stage is not considered here at all. Therefore, reasonable methods for calculating bearings should be based on the contact problems of the theory of elasticity for cylindrical bodies of close radii. This study aims to use the author's generalized computational method [4] and [17] to [23] to estimate tribocontact pressures and durability when the bearing wears. This method is based on the concept [4], [17] and [18] of near-surface layers frictionalfatigue destruction of tribosystem elements in the process of sliding friction. In particular, in [17], the author presented a method of approximate solution of cylindrical sliding tribosystem consisting of elements with small non-circularity of its contours for the first time. The model of the triboprocess and the method of calculating the contact pressures were considered; in [18], a set of different contact problems is considered, taking into account wear for cylindrical tribosystems consisting of elements with non-circular contours; in [19], a cumulative analytical model of wear and durability of plain bearings is presented and schemes of plain bearings with different faceting of the shaft and the bushing are investigated; in [20], a generalized method for solving the contact problem for a cylindrical joint with complex faceting is presented. The parameters of one- and two-region contact are determined; in [21], according to the author's cumulative model of wear of plain bearings with technological ovality of adjacent parts, the accuracy of calculations of their service life was evaluated. The developed express calculation method of the tribocontact interaction of the shaft and the bushing is given; in [22], the generalized cumulative model of research of wear kinetics for the plain bearings in the case of one- and two-region contact is given. The results of solving the nonclassical contact problem and the wear contact problem are presented; in [23], the solution of the wear-contact problem for a bearing with different faceting of the shaft is given. Using the cumulative model, the influence of the faceting on the service life of the bearing at the complete one-region and mixed-region contact was investigated.

Based on the above methods of solving a complex wear-contact problem of the theory of elasticity, an easier-to-implement engineering method is presented below.

\section{WEAR TRIBOKINETIC MODEL OF SLIDING FRICTION}

According to [4], the materials' wear kinetics in sliding tribosystem is described by a system of ordinary differential equation:

$$
\gamma_{k}=\frac{1}{v} \frac{\mathrm{d} h_{k}}{\mathrm{~d} t} \Phi_{k}(\tau)=1
$$

where $h_{k}$ is the linear wear function of tribosystem elements; $\gamma_{k}$ is the wear rate of their materials; $v$ is the sliding speed; $t$ is the triboprocess time; $\Phi(\tau)$ is the basic parameter of the model as the characteristic function of wear resistance of tribocouple materials; $k=1,2$ is the numbering of tribosystem elements.

The specific force of friction in mechanics and tribology is determined by the Amonton-Coulomb formula:

$$
\tau=f \sigma_{r},
$$

where $f$ is the sliding friction coefficient; $\sigma_{r}=-p(\alpha)$ is the contact stress calculated according to the methods of the elasticity theory; $p(\alpha)$ are the contact pressures.

The characteristic function $\Phi_{i}\left(\tau_{i}\right)$ of wear resistance of materials for discrete values of specific friction forces $\tau_{i}$ is established by the results of triboexperimental studies according to the method [18] and [19]:

$$
\Phi_{i}\left(\tau_{i}\right)=\frac{L_{i}}{h_{i}}
$$


where $L=v t$ is the friction path; $i=1,2,3, \ldots$ are the levels of load in the tribo-experiment.

Approximation of experimental values of wear resistance functions $\Phi_{i}\left(\tau_{i}\right)$ is carried out by the relation [18] and [19]:

$$
\Phi_{k}(\tau)=B_{k} \frac{\tau_{k 0}^{m_{k}}}{\left(\tau-\tau_{k 0}\right)^{m_{k}}},
$$

where $B_{k}, m_{k}, \tau_{k 0}$ are the wear resistance characteristics of materials in the tribocouple.

\section{FORMULATION OF A TRIBOCONTACT PROBLEM}

The arrangement of the sliding bearing is presented in Fig. 1. Shaft 2 rotates at a constant angular velocity $\omega_{2}$. Under the influence of the reduced external load $N=F / l$, the contact pressures $p(\alpha)$ unknown in distribution and magnitude arise in the contact area. There is the radial clearance $\varepsilon=R_{1}-R_{2}>0$ in the bearing. The materials of the shaft and the bushing usually have different elastic properties and different wear resistance. The bearing elements have different wear areas: the bushing 1 in the area $2 R_{2} \alpha_{0}$ and shaft 2 along the contour. The problem is solved as a plain problem of the elasticity theory, where the external load $F$ on the shaft is related to the length of the journal $l$.

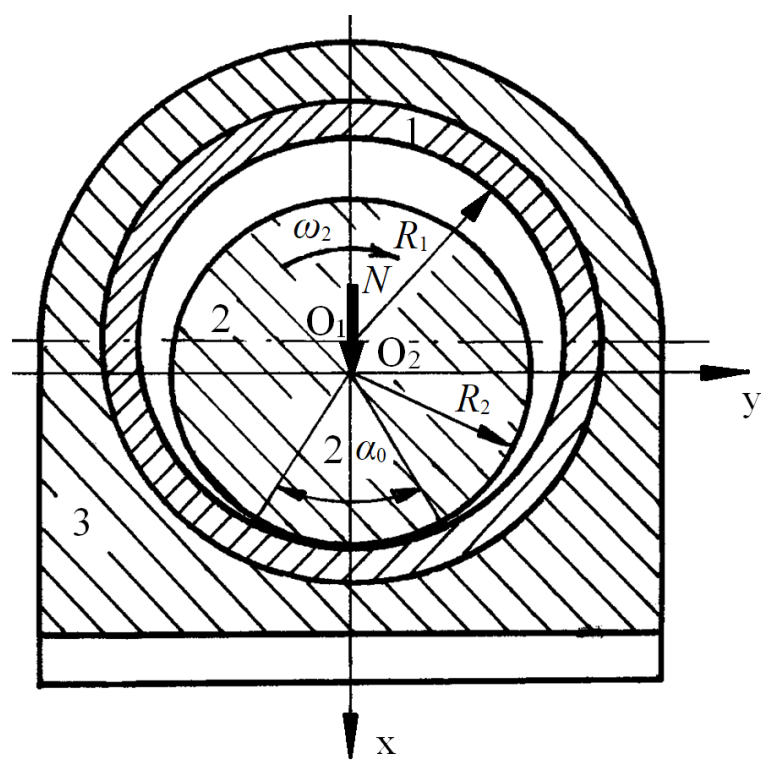

Fig. 1. Scheme of the sliding bearing

When solving the problem, it is necessary to determine: initial contact angle $2 \alpha_{0}$; maximum initial contact pressures $p(0)$; tribocontact angle
$2 \alpha_{0 h}$; maximum tribocontact pressures at wear $p(0, t, h)$; bearing durability $t$ at the accepted elements permissible wear $h_{k^{*}}$; bearing elements wear $h_{k}$ during the accepted service life $t$ *

According to the methods in [4], [18], and [20], the equilibrium Eq. (5) is used to determine the initial contact semi-angle $\alpha_{0}$ under the action of the reduced load $N=F / l$, the journal radius $R_{2}$ and the radial clearance $\varepsilon$.

$$
N=R_{2} \int_{-\alpha_{0}}^{\alpha_{0}} p(\alpha) \cos \alpha d \alpha=4 \pi R_{2} E \varepsilon \sin ^{2}\left(\frac{\alpha_{0}}{4}\right),
$$

where $E=\frac{e \cos ^{2}\left(\alpha_{0} / 4\right)}{R_{2}}, e=\frac{4 E_{1} E_{2}}{Z}, 0^{\circ}<\alpha_{0}<90^{\circ}$, $Z=\left(1+\kappa_{1}\right)\left(1+\mu_{1}\right) E_{2}+\left(1+\kappa_{2}\right)\left(1+\mu_{2}\right) E_{1}, \kappa_{k}=3-4 v_{k}$, $E_{k}, \mu_{k}$ are Young's modules and Poisson's ratios of shaft 1 and bearing bushing 2 materials. Eq. (5) is solved using the method of successive approximations, by ensuring the equality of its left and right parts with the accepted accuracy. Accordingly, to determine the maximum initial contact pressures $p(0)$, which characterize the bearing load-carrying capacity, the developed method uses the formula:

$$
p(0)=E \varepsilon \tan \left(\frac{\alpha_{0}}{2}\right) .
$$

Determining the tribocontact semi-angle $\alpha_{0 h}$ while shaft and bearing bushing wear is carried out by a similar dependence as for the contact semi-angle $\alpha_{0}$ :

$$
N=4 \pi R_{2} E\left(\varepsilon+C_{h} \varepsilon_{h}\right) \sin ^{2}\left(\frac{\alpha_{0 h}}{4}\right),
$$

where $\varepsilon_{h}=h_{k \max }\left(-K_{t}^{(k)}+h_{k}^{\prime}\right), \quad h_{1}^{\prime}=h_{2} / h_{1}, \quad K_{t}^{(1)}=1$, $K_{t}^{(2)}=\alpha_{0} / \pi$ are the overlap coefficients; $C_{h}>0$ is the wear rate indicator; $h_{1 *}$ is the permissible bushing wear:

$$
\begin{aligned}
& h_{1}^{\prime}=\frac{h_{2}}{h_{1}}=\frac{\Phi_{1}(\tau)}{\Phi_{2}(\tau)}=\frac{B_{1} \tau_{10}^{m_{1}}\left(\tau-\tau_{20}\right)^{m_{2}}}{B_{2} \tau_{20}^{m_{2}}\left(\tau-\tau_{10}\right)^{m_{1}}} K_{t}^{(2)}, \\
& h_{2}^{\prime}=\frac{h_{1}}{h_{2}}=\frac{\Phi_{2}(\tau)}{\Phi_{1}(\tau)}=\frac{B_{2} \tau_{20}^{m_{2}}\left(\tau-\tau_{10}\right)^{m_{1}}}{B_{1} \tau_{10}^{m_{1}}\left(\tau-\tau_{20}\right)^{m_{2}}} K_{t}^{(1)},
\end{aligned}
$$

where $\tau=f p(0)=f E \varepsilon \tan \left(\alpha_{0} / 2\right)$ is the maximum specific friction force acting at the wear process beginning when $t=0 ; h_{1}, h_{2}$ are the linear wear of bushing and shaft, respectively.

Maximum contact pressure $p(0, t, h)$ in the bearing at elements wear: 


$$
p(0, t, h)=p(0)+p(0, h) .
$$

The change in the maximum initial contact pressure $p(0, h)$ due to bearing elements wear is calculated as follows:

$$
p(0, h)=E C_{h} \varepsilon_{h} \tan \left(\frac{\alpha_{0 h}}{2}\right) .
$$

Since the bushing material is less wear-resistant than the shaft material and the bushing wears at a limited contact area, the bearing service life is determined by the bushing durability when it reaches the maximum permissible wear. According to [4], [22], and [23], taking into account the dependences, Eqs. (1), (2), (4), (6) and (9), the bearing service life $t_{*}$ is calculated by the formula:

$$
\begin{aligned}
t_{*} & =\frac{-B_{1} \tau_{01}^{m_{1}}}{v C_{h} S_{h}\left(-1+h_{1}^{\prime \prime}\right)\left(1-m_{1}\right) K_{t}^{(1)}} \times \\
& \times\left\{(S \varepsilon)^{1-m_{1}}-\left(S \varepsilon+C_{h} S_{h} \varepsilon_{h}\right)^{1-m_{1}}\right\},
\end{aligned}
$$

where $S=f \cdot p(0) / \varepsilon, S_{h}=f \cdot p(0, h) /\left(\varepsilon_{h} \cdot C_{h}\right), v=\omega \cdot R_{2}$.

If it is necessary to estimate the shaft wear $h_{2}$ along its entire contour over time $t_{*}$, the wear is calculated as follows (after the corresponding transformation of Eq. (10)):

$$
\begin{aligned}
h_{2} & =\mid \frac{1}{C_{h} S_{h}\left(K_{t}^{(2)}-h_{2}^{\prime \prime}\right) K_{t}^{(2)}} \times \\
& \times\left[\sqrt[1-m_{2}]{\frac{M_{2}(S \varepsilon)^{1-m_{2}}-t_{*}}{M_{2}}}-(S \varepsilon)\right],
\end{aligned}
$$

where $\quad M_{2}=\frac{B_{2} \tau_{02}^{m_{2}}}{v C_{h} S_{h}\left(1-m_{2}\right)\left(K_{t}^{(2)}-h_{2}^{\prime \prime}\right) K_{t}^{(2)}}, \quad$ and $h_{2}^{\prime}=K_{t}^{(2)} / K_{t}^{(1)} h_{1}^{\prime}$.

\section{RESULTS OF NUMERICAL SOLUTION}

Data for calculation: $N=25 \mathrm{~N}, 62.5 \mathrm{~N}, 125$ $\mathrm{N}, F=N l ; D_{2}=50 \mathrm{~mm} ; l=D_{2} ; \omega_{2}=1 \mathrm{~s}^{-1}$, $5 \mathrm{~s}^{-1} ; v=25 \mathrm{~mm} / \mathrm{s}, 125 \mathrm{~mm} / \mathrm{s} ; \varepsilon=0.125$ $\mathrm{mm}, 0.25 \mathrm{~mm} ; f=0.05$ at boundary friction; $h_{1 *}=0.5 \varepsilon ; C_{h}=0.05$.

Bushing material: teen bronze $E_{1}=1.2 \cdot 10^{5} \mathrm{MPa}$, $\mu_{1}=0.34 ; B_{1}=1.9 \cdot 10^{9}, m_{1}=0.76, \tau_{01}=0.1 \mathrm{MPa}$; shaft material: hardened steel $E_{2}=2.1 \cdot 10^{5} \mathrm{MPa}, \mu_{2}=0.3$; $B_{2}=4.9 \cdot 10^{9}, m_{2}=0.66, \tau_{02}=\tau_{01}$.

The calculation was performed according to the given flow diagram (Fig. 2).

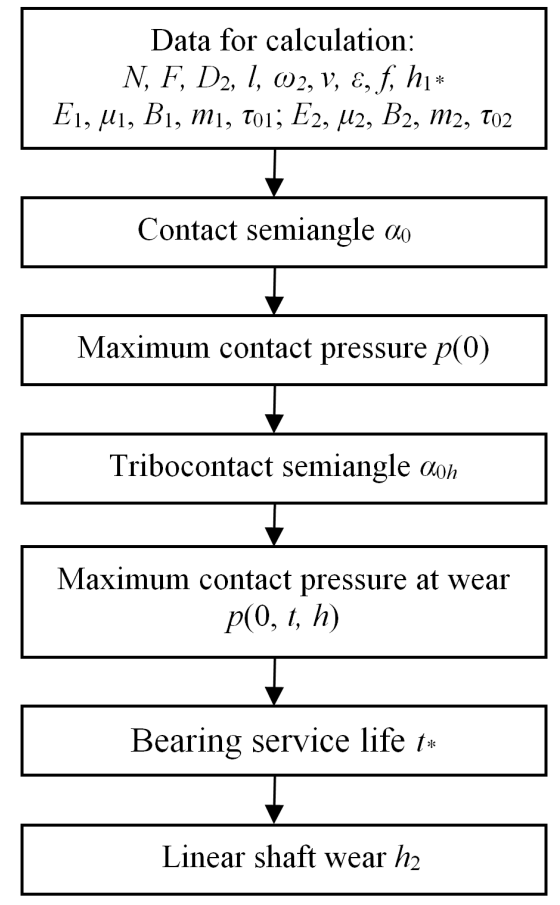

Fig. 2. The flow diagram

The results of solving the considered wearcontact problem are presented in Figs. 3 to 5 .

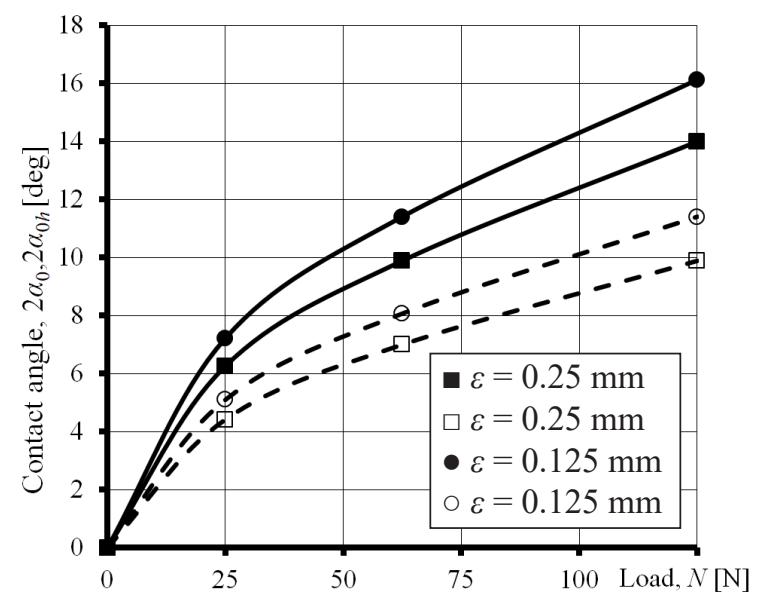

Fig. 3. Dependences of initial contact angles on loading and their changing at wear: $2 \alpha_{0}$ in dashed lines, and $2 \alpha_{0 h}$ in solid lines

For the initial contact angle $2 \alpha_{0}$ in the studied range of loads, there is an almost linear dependence in their increase. Naturally, with smaller radial clearances, these angles will be larger. When the accepted permissible wear is reached, the tribocontact angles $2 \alpha_{0 h}$ increase up to $\sqrt{2}$ times at both values of the radial clearances. 


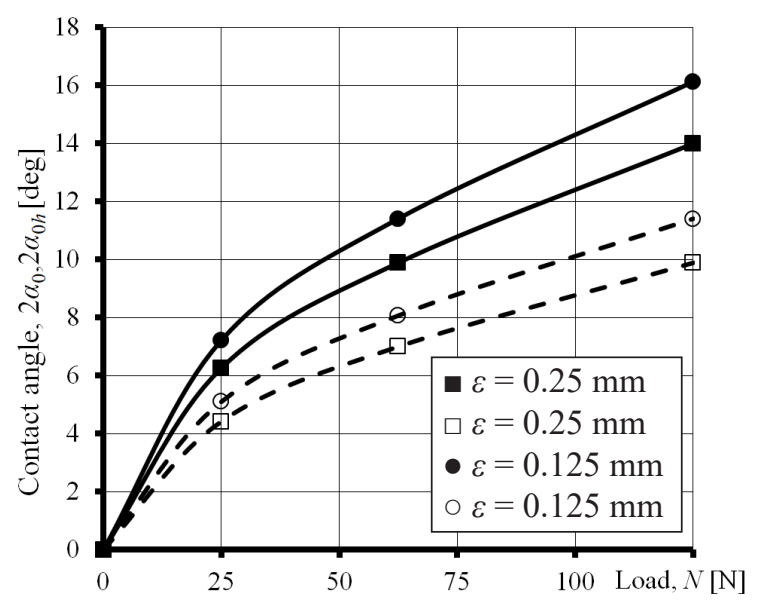

Fig. 4. Dependences of initial contact angles on loading and their changing at wear: $p(0)$ in dashed lines, $p(0, t, h)$ in solid lines

At relatively low loading, a nonlinear increase in the initial maximum pressures $p(0)$ is observed, and a further increase in the load leads to their linear increase. The wear of the bronze bushing contributes to a significant reduction in pressure. Tribocontact pressures $p(0, t, h)$ depend to varying degrees on radial clearance and wear.

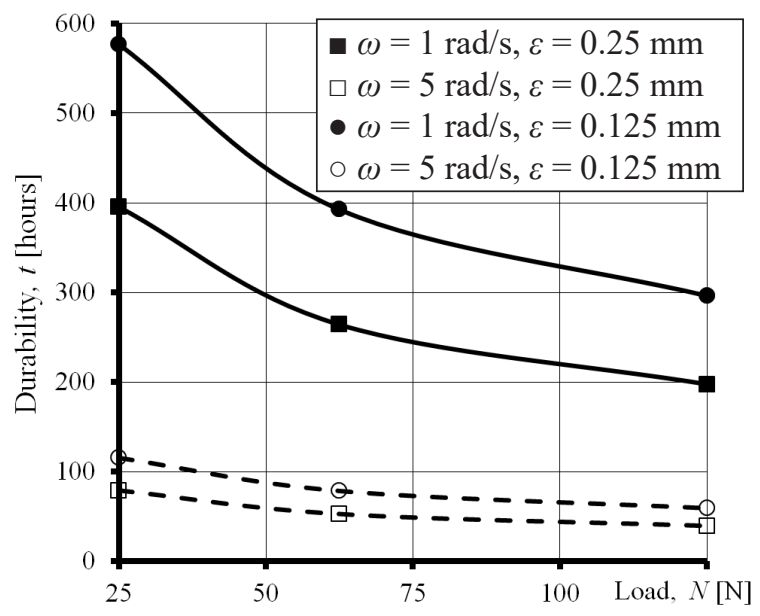

Fig. 5. Dependence of the bearing service life on loading

As the load increases, the bearing service life decreases nonlinearly. With a fivefold increase in angular velocity, there is a directly proportional decrease in service life.

\section{CONCLUSIONS}

1. The presented method of predictive estimation of sliding bearings load-carrying capacity and tribological durability allows carrying out substantiated and effective research on such basic factors of influence as external loading, shaft diameter, radial clearances, and wear.

2. An important feature of the method is the ability at the design stage to perform both the calculation of bearing service life, and the solution of inverse problem: the assessment of the bushing and shaft wear accepted service life. The solution is presented in a closed form, and this allows its implementation using the simplest software, starting from Excel (Figs. 3 to 5).

3. It should also be noted that the method (presented in Section 2) can be used without any restrictions not only for the calculation of bearings with metal elements, as presented above, but also when the friction surfaces are coated with different composition and purpose (protective, antifriction, wear-resistant) coatings.

4. On the basis of this method, it is possible to carry out the optimization on criteria of contact strength, wear resistance and durability, as well as an optimum choice of materials at the stage of the bearings designing. It is also very promising to use the method for hybrid bearings, with materials that are significantly different in their properties are used.

5. It is an advanced method for the calculation of metal-polymer bearing assemblies, because there are no calculation methods for such friction assemblies.

6. Solutions of this type of wear-contact problems can also be used to estimate the error of calculations obtained by various numerical methods (the finite element method, the boundary element method, etc.).

\section{REFERENCES}

[1] Lawrowski, Z. (2007). Sliding bearings. History, current state, development prospects. Tribologia, vol. 26, no. 6, p. 7-61.

[2] Cherepova, T., Dmitrieva, G., Tisov, O., Dukhota, O., Kindrachuk, M. (2019). Research on the properties of Co-TiC and Ni-TiC HIP-sintered alloys. Acta Mechanica et Automatica, vol. 13, no. 1, p. 57-67, D0l:10.2478/ama-2019-0009.

[3] Panarin, V. Ye., Kurdyumov, G.V., Svavil'nyy, M. Ye., Khominych, A.I., Kindrachuk, M.V., Kornienko, A.0. (2017). Creation of a diffusion barrier at the interphase surface of composite coatings reinforced with carbon nanotubes. Journal of Nano- and Electronic Physics, vol. 9, p. 06023-1-06023-5, D0l:10.21272/jnep.9(6).06023.

[4] Andreikiv, A.E., Chernets, M.V. (1991). Evaluation of the Contact Interaction of Rubbing Machine Elements. Naukova Dumka, Kiev. 
[5] Kuzmenko, A.G. (2010). Development of Methods of Contact Tribomechanics. KhNU, Khmelnytsky.

[6] Zwieżycki, W. (1999). Predicting the Reliability of Wearing Machine Elements. Institute for Sustainable Technologies, Radom.

[7] Dykha, A., Sorokatyi, R., Makovkin, O., Babak, O. (2017). Calculation-experimental modeling of wear of cylindrical sliding bearings. Eastern-European Journal of Enterprise Technologies, vol. 5, no. 1, p. 51-59, D0l:10.15587/17294061.2017.109638.

[8] Dykha, A., Marchenko, D. (2018). Prediction the wear of sliding bearings. International Journal of Engineering \& Technology, vol. 7, no. 2.23, p. 4-8, D0l:10.14419/ijet.v7i2.23.11872.

[9] Rezaei, A., Ost, W., Van Paepegem, W., De Baets, P., Degrieck, J. (2011). Experimental study and numerical simulation of the large-scale testing of polymeric composite journal bearings: Three-dimensional and dynamic modelling. Wear, vol. 270, no. 7-8, p. 431-438, D0I:10.1016/j.wear.2010.11.005.

[10] Rezaei, A., Ost, W., Van Paepegem, W., De Baets, P., Degrieck, J. (2012). A study on the effect of the clearance on the contact stresses and kinematics of polymeric composite journal bearings under reciprocating sliding conditions. Tribology International, vol. 48, p. 8-14, D0l:10.1016/j. triboint.2011.06.031.

[11] Rezaei, A., Van Paepegem, W., De Baets, P., Ost, W., Degrieck, J. (2012). Adaptive finite element simulation of wear evolution in radial sliding bearing. Wear, vol. 296, no. 1-2, p. 660-671, DOI:10.1016/j.wear.2012.08.013.

[12] Sorokatyi, R.V. (2002). Modeling the behavior of tribosystems using the method of triboelements. Journal of Friction and Wear, vol. 23, no. 1, p. 16-22.

[13] Sorokatyi, R.V. (2003). Solution of the problem of wear of a fine elastic layer with a rigid bearing mounted on a rigid shaft using the method of triboelements. Journal of Friction and Wear, vol. 24, no. 1, p. 35-41.

[14] Sorokatyi, R.V. (2003). Evaluation of efficiency of sliding bearings during reciprocation. Journal of Friction and Wear, vol. 24 , no. 2, p. 136-143.
[15] Sorokatyi, R., Chernets, M., Dykha, A., Mikosyanchyk, 0. (2019). Phenomenological model of accumulation of fatigue tribological damage in the surface layer of materials. Mechanisms and Machine Science, vol. 73, p. 3761-3769, DOI:10.1007/978-3-030-20131-9_371.

[16] Dykha, A., Sorokatyi, R., Pasichnyk, 0., Yaroshenko, P., Skrypnyk, T. (2020). Machine wear calculation module in computer-aided design systems. IOP Conference Series Materials Science and Engineering, vol. 1001, art. ID 012040, DOI:10.1088/1757-899X/1001/1/012040.

[17] Chernets, M.V. (1996). On the issue of assessing the durability of cylindrical sliding tribosystems with boundaries close to circular. Friction and Wear, no. 3, p. 340-344.

[18] Chernets, M.V. (2009). Contact Problems for Cylindrical Systems with Low Angularity of Contours When Worn. Drohobycz State Pedagogical University, Lviv.

[19] Chernets', M.V., Andreikiv, O.E., Liebiedieva, N.M., Zhydyk, V.B. (2009). A model for evaluation of wear and durability of plain bearing with small non-circularity of its contours. Materials Science, vol. 2, p. 279-290, D0I:10.1007/s11003-009-9176-5.

[20] Chernets', M.V. (2009). Contact problem for a cylindrical joint with technological faceting of the contours of its parts. Materials Science, vol 45, p. 859-868, D0I10.1007/s11003. 010-9252-x.

[21] Chernets', M.V., Zhydyk, V.B., Chernets', Yu.M. (2014). Accuracy of evaluation of the service life of a plain bearing according to the generalized cumulative model of wear. Materials Science, vol. 50, p. 39-45, D0l:10.1007/s11003014-9689-4.

[22] Chernets, M., Chernets, Ju. (2015). Generalized method for calculating the durability of sliding bearings with technological out-of-roundness of details. Proceedings of the Institution of Mechanical Engineers, Part J: Journal of Engineering Tribology, vol. 229, no. 2, p. 216-226, Dol:10.1177/1350650114554242.

[23] Chernets, M.V. (2015). Prediction of the life of a sliding bearing based on a cumulative wear model taking into account the lobing of the shaft contour. Journal of Friction and Wear, vol. 36, p. 163-169, D0l:10.3103/S1068366615020038. 